\title{
Company Profit Prediction Based On Forecasting Of Port Throughput Using Time Series-Adaptive Neuro Fuzzy Inference System
}

\author{
Victory Tyas Pambudi Swindiarto and Mohammad Isa Irawan \\ Department of Management Technology, Institut Teknologi Sepuluh Nopember, Indonesia \\ e-mail: vicdc19@gmail.com
}

\begin{abstract}
As a maritime country, ports play an important role in economic development in Indonesia. Throughput is an important factor affecting Port Profits. This prediction is needed in an effort to find out the company's prospects, help estimate the long-term profitability of representatives, predict earnings, and estimate risk in investment. In this research, forecasting data throughput will be carried out, such as container traffic, number of ships, export traffics, goods traffic, animal flow and passenger traffic for the next year using Time Series-Adaptive Neuro Fuzzy Inference System (TS-ANFIS) as an input parameter in the decision support system. Before predicting the benefits of the port using the ANFIS method, principal component analysis (PCA) was applied to reduce parameters that did not sufficiently affect the profits of the port. The data used are time series data from 2009 to 2018 . From the system built it is expected to be able to provide good results in predicting the value of port throughput using TS-ANFIS and to predict profit values using the ANFIS method. The best results from profit prediction using ANFIS obtained R2 of 0.947, RMSE of 28524582.39, MAPE of $14.74 \%$ and MAAPE of 0.145 . From the prediction results, it can be used as a reference for company projections in investing, managing cash flow, managing assets and global bonds.
\end{abstract}

Keywords-ANFIS, PCA, Time Series, Throughput, Port, Profit.

\section{INTRODUCTION}

A CCORDING to Yeremia, the maritime sector plays a role of 20.02 percent which has the potential to become a leading sector and has a value-added of 19.34 percent in the Indonesian economy [1]. As a maritime country, ports play an important role in economic development in Indonesia. Substantial factors that affect port profits include throughput and investment. Data throughput at the port includes data on container traffic, exports, goods traffic, passenger traffic and others. Throughput data becomes an index to measure port development, manage production, development planning and construction [2]. Throughput data is historical data that can be applied to estimate future value [3]. The good port throughput forecasting can affect the port to improve port economic development, logistical competitiveness, and work efficiency [4]. The potential of a port can be determined by estimating the risk in investment and predicting the benefits of the port. Prediction is needed as an effort to find out the company's prospects, help estimate the ability of representative income in the long run, income prediction, and estimate risk in investment.

Zhao Jin and Yaozong Ding used a time series analysis by (a)

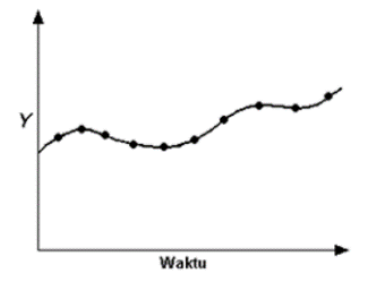

(c)

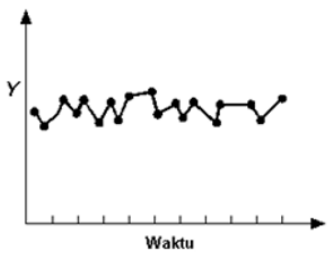

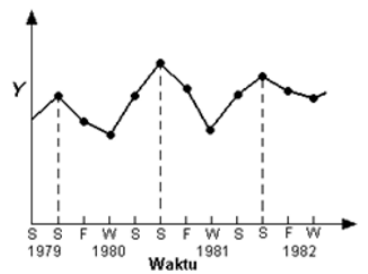

(b)

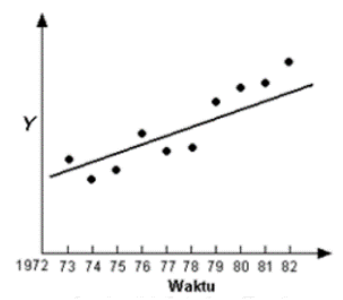

(d)
Figure 1. Types of Data Patterns: (a) Horizontal Data Patterns; (b) Seasonal Data Patterns (c) Cycle Data Patterns; (d) Trend Data Pattern.

applying the SARIMA (Seasonal Autoregressive Moving Average Model) model to predict Container Throughput in China [5]. Xin Dong et al. Predicted LTE network throughput by applying the Integrated Moving Average Autoregressive Model (ARIMA) and exponential smoothing [6]. Regressionbased models have traditionally been widely used in predicting similar problems, but these models do not have the learning ability (intelligence) [4] Artificial Intelligence is currently being developed widely by technology experts in the world, the system built is a Machine Learning which allows the process of learning and developing based on big data and corrections from previous mistakes [7]. Therefore, several methods of computational intelligence are widely used for pattern recognition, forecasting, and decision making systems. Artificial Neural Network (ANN) is widely used because it has a unique model. The model built by ANN can be used to approach non-linear functions until it reaches the desired level of accuracy and it can be applied to complex models [8].

Xi Zha, et al combined the SARIMA linear model with the non-linear ANN model to predict time series data from Container Throughput [3]. The combination of fuzzy logic and ANN methods is called Adaptive Neuro Fuzzy Inference System (ANFIS). ANFIS can be used to predict time series, such as the stock market, maritime weather, and others. The application of the ANFIS method in several research concerning the stock market forecasting of the stock exchange in Istanbul resulted in an accuracy of $98.3 \%$ [9], Maritime 
The $1^{\text {st }}$ International Conference on Business and Engineering Management (IConBEM)

February $1^{\text {st }} 2020$, Institut Teknologi Sepuluh Nopember, Surabaya, Indonesia

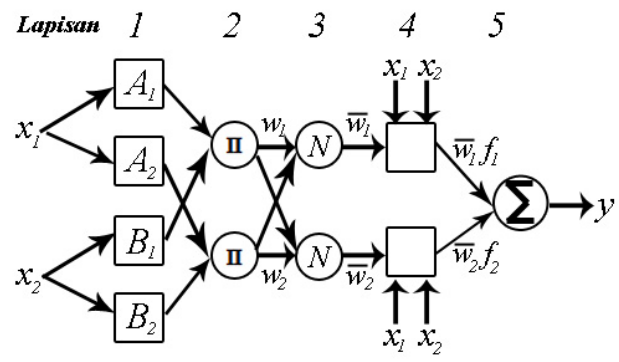

Figure 2: ANFIS Architecture.

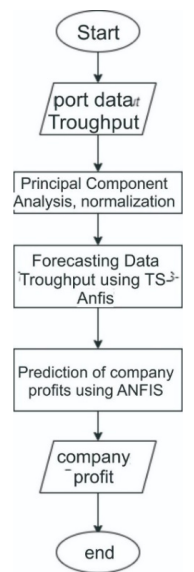

Figure 3: Throughput Forecasting System Design using TS-ANFIS

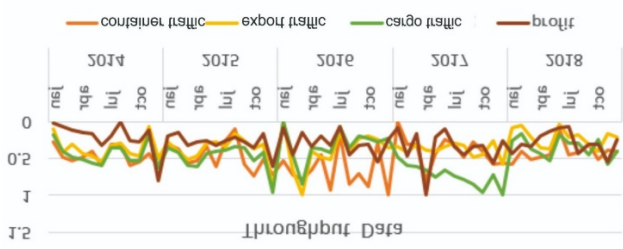

Figure 4: Throughput Data

weather prediction in Java produces the smallest average error value of 0.00122 [10], closing price index predictions on the stock exchange [11], time series predictions from internet traffic [12], and the others. Based on several previous research, this research will build a decision support system using the Adaptive Neuro Fuzzy Inference System method to predict the benefits of the port based on the results of forecasting data throughput one year in the future using the Time Series-Adaptive Neuro Fuzzy Inference System.

\section{METHOD}

\section{A. Time Series}

Time series data (time series) is a type of data that is collected in chronological order in a certain time span. Time is seen as discrete (time can be modeled is continuous) and the frequency of collection is always the same. In a discrete case, the frequency can be in seconds, minutes, hours, days, weeks, months or years. Time series analysis and forecasting are active fields of research in which accuracy in time series forecasting is the subject of the decision making process. Some research that conducts research on time series are statistics, neural networks, and fuzzy systems. These methods have different advantages and disadvantages. Especially
Table 1.

Learning Process Hybrid ANFIS

\begin{tabular}{ccc}
\hline \hline & Forward & Backward \\
\hline Premise Parameters & permanent & Gradient \\
Consequent & Descent \\
Parameters & Output Loop & permanent \\
Signal & Output Loop \\
\hline \hline
\end{tabular}

Table 2.

Initial Eigenvalues Reslut

\begin{tabular}{cccc}
\hline \hline Component & \multicolumn{3}{c}{ Initial Eigenvalues } \\
\cline { 2 - 4 } & Total & $\begin{array}{c}\text { \% of } \\
\text { Variance }\end{array}$ & $\begin{array}{c}\text { Cumulative } \\
\%\end{array}$ \\
\hline 1 & 2.640 & 37.712 & 37.712 \\
2 & 1.485 & 21.212 & 58.924 \\
3 & 1.030 & 14.721 & 73.645 \\
4 & 0.858 & 12.261 & 85.906 \\
5 & 0.466 & 6.656 & 92.562 \\
6 & 0.364 & 5.196 & 97.758 \\
7 & 0.157 & 2.242 & 100.000 \\
\hline \hline
\end{tabular}

Table 3 .

Profit Forecasting Results with Genfis 2

\begin{tabular}{cccc}
\hline \hline & \multicolumn{3}{c}{ Component } \\
\cline { 2 - 4 } & 1 & 2 & 3 \\
\hline Container & .884 & & .275 \\
Number of Ships & .799 & .116 & -.219 \\
Passenger Traffic & -.631 & -.223 & .127 \\
Cargo Trafic & & .944 & \\
Ekspor Trafic & .312 & .850 & -.874 \\
Animal Trafic & & & .782 \\
Profit & .138 & .115 & \\
\hline \hline
\end{tabular}

problems in the real world often become complex problems and one model may not be able to solve the problem properly. According to Pakaja et al, Forecasting is a process for estimating future needs which include the measurement of quantity, quality, time and location needed in order to meet the demand for goods or services, to predict this accurate data is needed in the past, and to be able to see the situation in the future. Types of time series data patterns can be seen in Figure 1.

\section{B. Data Transformation}

To adjust the data values with the range of activation functions used in the network system that is built, it is necessary to transform the data and make the data spread evenly. There are several types of data transformation, namely polynomial transformation, normal transformation and linear transformation. Data normalization is done with the aim of disappearing duplication of data, reducing complexity and simplifying data modification [13]. To normalize data into intervals $[0,1]$ use equation 1 , where $x$ is data after normalized with $x_{p}$ is the original value of data that has not been normalized, $\min \left(x_{p}\right)$ is the minimum value of the data set and $\max \left(x_{p}\right)$ is the maximum value of the data set [14].

$$
x=\frac{\left(x_{p}-\min \left(x_{p}\right)\right)}{\left(\max \left(x_{p}\right)-\min \left(x_{p}\right)\right)}
$$

In addition to normalization, data normalization is important so that the forecasting data can be seen easily in the same value as the origin. Equation 2 shows the formula for normalizing data into intervals $[0,1]$.

$$
x=\left(x_{p}\right) \times\left(\max \left(x_{p}\right)-\min \left(x_{p}\right)\right)+\min \left(x_{p}\right)
$$


The $1^{\text {st }}$ International Conference on Business and Engineering Management (IConBEM)

February $1^{\text {st }} 2020$, Institut Teknologi Sepuluh Nopember, Surabaya, Indonesia

Table 4

Time Series Pattern Sample Data

\begin{tabular}{cccc}
\hline \hline$X_{t-3}$ & $X_{t-2}$ & $X_{t-1}$ & $X_{t}$ \\
\hline 0.272 & 0.482 & 0.531 & 0.488 \\
0.482 & 0.531 & 0.488 & 0.395 \\
0.531 & 0.488 & 0.395 & 0.598 \\
0.488 & 0.395 & 0.598 & 0.299 \\
0.395 & 0.598 & 0.299 & 0.306 \\
0.598 & 0.299 & 0.306 & 0.596 \\
\hline
\end{tabular}

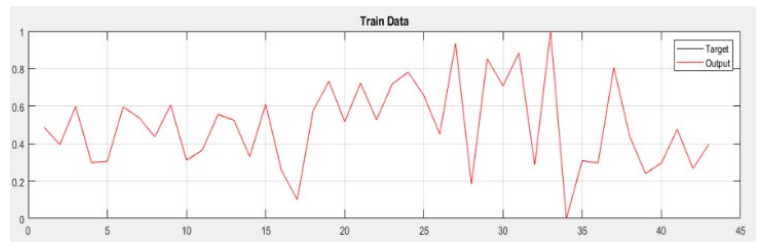

Figure 7: Graph of Container Data Training Results.

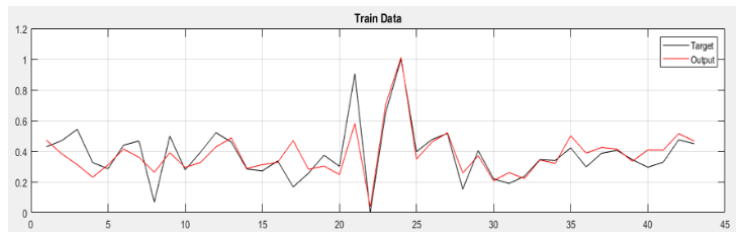

Figure 8: Export Traffic Data Training Results Chart.

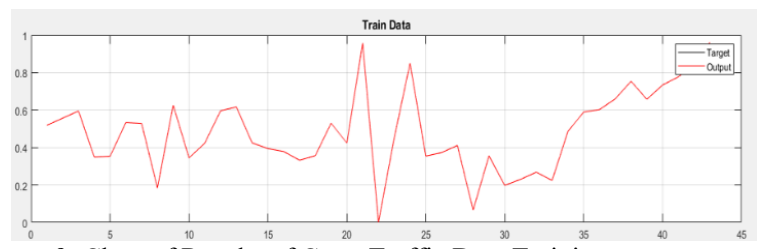

Figure 9: Chart of Results of CargoTraffic Data Training.

where $x$ is the data value after denormalization, $x_{p}$ is the output data before denormalization, $\min \left(x_{p}\right)$ is the minimum data in the data set before normalization and $\max \left(x_{p}\right)$ is the maximum data in the data set before normalization [14].

C. Principal Component Analysis (PCA)

Principal Component Analysis (PCA) is a pattern recognition technique in data [15]. One application of PCA is to analyze high-dimensional data that is difficult to understand just by looking at large amounts of data by showing differences and similarities between patterns [16]. Basically, PCA is used to reduce largely correlated variables to smaller using linear algebraic techniques and can explain correlations between data, where rows represent samples of the data and columns represent variables from the data. These correlated variables are called principal components [17].

The steps of the PCA algorithm will be explained below:

1. Find Mean Adjusted Data (B)

$\mathrm{B}$ is obtained by calculating the difference between the data with the average of each dimension and the data obtained with a zero-mean value.

$$
B=x-\bar{x}
$$

Where $x$ is the data used and $\bar{x}$ is the average of all sample data for each dimension.

2. Look for the covariant matrix (C) with equations (4)

$$
C=\frac{1}{n-1} B^{\prime} B
$$

Where $\mathrm{n}$ is the total data, $\mathrm{B}$ is the Mean Adjusted Data matrix and $B^{\prime}$ is the transpose of the matrix $B$.
Table 5 .

Throughput Forecasting Results using TS-ANFIS

\begin{tabular}{clcc}
\hline \hline Data & ANFIS Parameter & MSE & RMSE \\
\hline \multirow{3}{*}{ Container Traffic } & Genfis 1, 2 mf & 7431.9 & 86.20 \\
& Genfis 2, radius 0.1 & 4543.6 & 67.40 \\
& Genfis 3, 2 mf & 6147.0 & 78.40 \\
& Genfis 1, 5 mf & $5.44 \times 10^{-10}$ & $2.33 \times 10^{-5}$ \\
Export Traffic & Genfis 2, radius 0.2 & $4.17 \times 10^{-11}$ & $6.46 \times 10^{-6}$ \\
& Genfis 3, 4 mf & $4.30 \times 10^{-10}$ & $2.07 \times 10^{-5}$ \\
& Genfis 1, 3 mf & $7.35 \times 10^{-9}$ & $8.57 \times 10^{-5}-$ \\
Cargo Traffic & Genfis 2, radius 0.2 & $9.89 \times 10^{-13}$ & $9.94 \times 10^{-7}-$ \\
& Genfis 3, 5 mf & $2.28 \times 10^{-11}$ & $4.77 \times 10^{-5}$ \\
\hline \hline
\end{tabular}

Table 6.

Profit Forecasting Results with Genfis 1 Gaussian Membership Function

\begin{tabular}{ccccc}
\hline \hline $\begin{array}{c}\text { Number } \\
\text { mf }\end{array}$ & $\boldsymbol{R}^{\mathbf{2}}$ & RMSE & MAPE & MAAPE \\
\hline 2 & 0,942 & 29877682,905 & $14,96 \%$ & 0,147 \\
3 & 0,758 & 60968529,940 & $25,92 \%$ & 0,235 \\
4 & 0,823 & 52071102,048 & $26,35 \%$ & 0,250 \\
5 & 0,917 & 35710845,544 & $17,812 \%$ & 0,173 \\
6 & 0,794 & 56247837,319 & $25,27 \%$ & 0,233 \\
7 & 0,853 & 47544376,566 & $26,54 \%$ & 0,256 \\
8 & 0,872 & 44260090,767 & $23,79 \%$ & 0,230 \\
9 & 0,844 & 48895961,213 & $26,24 \%$ & 0,252 \\
10 & 0,864 & 45648057,865 & $23,97 \%$ & 0,231 \\
\hline \hline
\end{tabular}

Table 7.

Profit Forecasting Results with Genfis 1 Generalized Bell Membership Function

\begin{tabular}{ccccc}
\hline \hline $\begin{array}{c}\text { Number } \\
\mathrm{mf}\end{array}$ & $\boldsymbol{R}^{2}$ & RMSE & MAPE & MAAPE \\
\hline 2 & 0,881 & 42671069,17 & $20,49 \%$ & 0,197 \\
3 & $-213,419$ & 1813365574,4 & $525,91 \%$ & 0,755 \\
4 & $-4,379$ & 287217700,33 & $122,65 \%$ & 0,634 \\
5 & 0,714 & 66206824,58 & $29,75 \%$ & 0,269 \\
6 & 0,856 & 46919208,38 & $26,71 \%$ & 0,258 \\
7 & 0,920 & 35106520,31 & $19,63 \%$ & 0,192 \\
8 & 0,895 & 40109405,27 & $20,55 \%$ & 0,199 \\
9 & 0,908 & 37648177,36 & $19,52 \%$ & 0,190 \\
10 & 0,903 & 38649686,84 & $21,24 \%$ & 0,207 \\
\hline \hline
\end{tabular}

3. Extract the eigenvalue and eigenvector with the equation (5)

$$
\begin{aligned}
C-\lambda I & =0 \\
(C-\lambda I) x & =0
\end{aligned}
$$

Where $I$ is an identity matrix, $\lambda$ is eigenvalue and $\mathrm{x}$ is eigenvector. Then sort the eigenvector based on eigenvalue [18].

4. Select the principal component using the method to build feature vectors

$$
V_{m}=\left[e i g_{1}, e i g_{2}, e i g_{3}, \ldots, e i g_{m}\right]
$$

Where $V_{m}$ is a feature vector, eig is an eigenvector and $\mathrm{m}$ is the number of selected principal components.

5. Finding the final data using the equation (8)

$$
D=\left(V_{m}\right)^{T}(B)^{T}
$$

The final data is the original data that matches the selected eigenvector.

\section{Adaptive Neuro Fuzzy Inference System}

Adaptive Neuro Fuzzy Inference System (ANFIS) is an architecture that is functionally the same as the first order Takagi-Sugeno fuzzy inference system model [11]. The advantage of a fuzzy inference system is that it can translate knowledge from experts in the form of rules, but it usually takes a long time to determine its membership function, which 
The $1^{\text {st }}$ International Conference on Business and Engineering Management (IConBEM)

February $1^{\text {st }} 2020$, Institut Teknologi Sepuluh Nopember, Surabaya, Indonesia

is combined with artificial neural networks, therefore, it can reduce search time.

The architecture of ANFIS is the same as an artificial neural network with a radial function and a few specific limitations shown in Figure 2 [19].

ANFIS architecture consists of 5 layers, the layer symbolized by a square is an adaptive layer (parameters can change). While the layer symbolized by a circle is nonadaptive (fixed parameters).

1.) Layer 1

Each node $i$ on this layer is an adaptive node with a function node:

$$
\begin{aligned}
& O_{l, i}=\mu_{A, i}\left(x_{i}\right), i=1,2, \\
& O_{l, i}=\mu_{B, i}\left(x_{i}\right), i=3,4
\end{aligned}
$$

Where $x$ and $y$ are the input values for the node and $A i$ or $B i$ are fuzzy sets. The membership function that is commonly used is the type of Gaussian membership function [20].

$$
\mu(x)=\frac{1}{1+\left|\frac{x-c}{a}\right|^{2}}
$$

The parameters $a, b, c$, in the gauss membership function are called adaptive premise parameters. the function of each node in layer 1 raises the degree of membership (premise part)[12].

\section{2.) Layer 2}

Each node in this layer is labeled $\Pi$ with the output being the multiplication of all incoming signals, i.e.:

$$
O_{2, i}=w i=\mu_{A, i}\left(x_{i}\right) \Delta \mu_{B, i}\left(x_{i}\right), i=1,2, \ldots
$$

Therefore:

$$
\begin{gathered}
w_{1}=\mu_{A, 1}\left(x_{1}\right) A N D \mu_{B, 1}\left(x_{2}\right) \\
w_{2}=\mu_{A, 2}\left(x_{1}\right) A N D \mu_{B, 2}\left(x_{2}\right)
\end{gathered}
$$

Each node output states the weight strength of a rule. Generally, the AND operation is used as a function node on this layer [21].

\section{3.) Layer 3}

Each node in this layer is given an $N$. notation The $i$-th node calculates the ratio of the $i$-weighting weight to the sum of all weights [22]:

$$
O_{3, i}=\overline{w_{l}}=\frac{w_{i}}{w_{1}+w_{2}}, i=1,2, \ldots
$$

The output of this layer is called weighting normalization.

\section{4.) Layer 4}

Each node $i$ on this layer is an adaptive node with a function node [23]:

With:

$$
O_{4, i}=\overline{w_{l}} y_{i}=\overline{w_{l}}\left(p_{i} x_{1}+q_{i} x_{2}+r_{i}\right)
$$

$\overline{w_{l}} \quad$ : normalized weights from layer 3

$\left(p_{i}+q_{i}+r_{i}\right)$ : parameter set of this node.

The parameters in this layer are called consequent parameters.

5.) Layer 5

At this layer there is only one fixed node whose function is to add all entries. Node function:

$$
O_{5, i}=\sum \overline{w_{l}} y_{i}=\frac{\sum \overline{w_{l}} y_{i}}{\sum \overline{w_{l}}}, i=1,2, \ldots
$$

The five-layer adaptive network is equivalent to the Takagi-Sugeno order fuzzy inference system 1 [24].

\section{E. Hybrid Learning Algorithm}

Hybrid learning methods are used to set ANFIS parameters in the forward or backward stages. Hybrid learning consists of two parts which can be seen in Table 1 .

$F$. Learning the direction of the forward pass with the Recursive Least Squares Estimator (LSE) method

From the ANFIS architecture (Figure 2), if the value of the premise parameter is fixed, then the overall output can be expressed by a linear combination of the consequent parameters. Here is the equation:

$$
y=\frac{w_{1}}{w_{1}+w_{2}} y_{1}+\frac{w_{2}}{w_{1}+w_{2}} y_{2}=\overline{w_{l}}\left(p_{1} x_{1}+q_{1} x_{2}+r_{1}\right)
$$

\section{G. Backward pass learning with the Gradient Descent method}

In the backward pass learning, the adaptive network is trained to get parameter values a and $c$, by taking the value $b$ $=2$. It can be seen in equation (9) to make improvements to a and $\mathrm{c}$, the error propagation model (backpropagation) ) with the gradient descent concept.

\section{H. Mean Absolute Percentage Error (MAPE)}

Mean Absolute Percentage Error (MAPE) is the percentage of average error forecasting results. Error is defined as the actual data value minus the forecast value. MAPE is calculated by finding the absolute error for each period. Then divide it by the observed value in that period and finally average the absolute percentage stated in equation 17 .

$$
M A P E=\frac{1}{n} \sum_{t=}^{n} \mid \text { Actual }- \text { Forecast } \mid
$$

This approach is very useful if the size of the forecasting variable is an important factor in evaluating the accuracy of the forecast. This assessment is easy to understand because it displays an error value in the form of a percentage. MAPE has managerial appeal and is a measure commonly used in forecasting. The smaller MAPE, the better the estimate. MAPE can also be used to compare the accuracy of the same or different techniques in two different series.

I. $\quad R$-Square $\left(R^{2}\right)$

R-square obtained through equations (18)

$$
R^{2}=\frac{\sum\left(Y_{\text {forecast }}-Y_{\text {mean }}\right)^{2}}{\sum\left(Y_{\text {actual }}-Y_{\text {mean }}\right)^{2}}
$$

J. Root Mean Square Error (RMSE)

Root Mean Square Error (RMSE) obtained through equations (2.21)

$$
R^{2}=\sqrt{(\text { forcast }- \text { actual })^{2}}
$$

\section{RESULT AND DISCUSSION}

Throughput and profit forecasters are processed using the ANFIS method. Prediction and forecasting are performed descriptive statistical presentation of the data to determine its characteristics. The analysis used to predict company profits and port throughput forecasting use TS-ANFIS. In this research, the data used are the variables of monthly throughput and port profits from 2009 to 2018 that data contains ship traffic, container traffic, export traffic, cargo traffic, passenger traffic, animal traffic, and profit. The design of forecasting data throughput systems using TS-ANFIS can be seen in Figure 3. 
The $1^{\text {st }}$ International Conference on Business and Engineering Management (IConBEM)

February $1^{\text {st }} 2020$, Institut Teknologi Sepuluh Nopember, Surabaya, Indonesia

Furthermore, to find out the pattern of the data used the PCA technique. PCA is a technique used to reduce variables that are not correlated and become simpler dimensions. Data analyzed were in the form of container data, export traffic, goods traffic, passenger traffic, animal traffic, and the number of ships at the Port of Tanjung Perak Surabaya. The reduction phase is processed after first analyzing the process based on the correlation matrix between variables. The greater the correlation between one variable with another variable, the more likely it is to produce an accurate forecasting model. In order for the analysis to be used precisely, it is expected that each input variable must be correlated between one variable with another variable. Based on the results of the PCA, the variables that correlate with profit are container traffics, traffics, exports and goods traffic and the data distribution used and normalized can be seen in Figure 4.

The stages used in this research are the formation of time series data patterns, the prediction of each parameter using TS-ANFIS, the prediction of profit value by using 3 parameter inputs using ANFIS.

\section{A. Principal Components Analysis}

Furthermore, to find out the pattern of the data used the PCA technique. PCA is a technique used to reduce variables that are not correlated so that they become simpler dimensions. Data analyzed were in the form of container data, export flow, goods flow, passenger flow, animal flow, and the number of ships at the Port of Tanjung Perak Surabaya. Before the reduction process is carried out, the analysis process is first performed based on the correlation matrix between variables. The greater the correlation between one variable with another variable, the more likely it is to produce an accurate forecasting model. In order for the analysis to be used precisely, it is expected that each input variable must be correlated between one variable with another variable.

Then in the reduction process, the first thing to do is to do the KMO and Barlett Test on the input data to determine the accuracy of the data using PCA in the reduction process. The results of the KMO test and the Barlett Test are represented in the following table. In Table 4.3 shows the significance value of 0.523 which means that the input data has fulfilled the requirements to reduce the variable using PCA that is KMO value $\geq 0.5$.

Next, the correlation value of each variable is calculated and formed in a correlation matrix. This correlation matrix will show the eigenvalue of each input variable and the number of variables that can be formed using PCA based on more than one eigenvalue shown in Table 2.

Based on Table 2, there are two components that have a greater eigenvalue equal to $1,2,640$ with a variance value of $37,712 \%$, and 1,485 with a variance value of $21,212 \%$. This shows that input variables can be categorized into two main component variables. Furthermore, to find out the variables to be reduced, a factor rotation (transformation) will be performed using the varimax factor rotation methodology. The results of the rotation factor are shown in table 3.

Based on table 3 shows the relationship between the original variable and the main component variable formed by PCA and called the loading value. The loading value chosen is a value of more than 0.5 , where this value is considered capable of explaining variables that affect profit. While variables that have a loading value of less than 0.5 are considered incapable or less influential on profit. Variables that have a loading value on component 1 are less than 0.5 , namely passenger flow, number of ships, and animal flow. So the variable reduced based on PCA technique is passenger flow, animal flow and the number of ships. The initial variables, amounting to six, namely the flow of goods, export flows, passenger flows, containers, number of ships, animal flows have been reduced to three variables namely the flow of goods, export flows and containers.

\section{B. Creating of Time Series Data Patterns}

The first process is the formation of time series data patterns a input training and target throughput forecasting every three months. The time series pattern is established on three data obtained from the PCA process, such as container data, export traffics, and goods traffic. time series patterns of container data, export traffics and the traffic of goods built are data at time $t-3, t-2$ and $t-1$ with the target $t$ you want to predict. Potential data is data from the previous 3 months. The results of forming data patterns can be seen in Table 4 .

From the data in the above table divided into two such as training data and testing data with $75 \%$ : $25 \%$ data sharing. The amount of training data from each parameter is 43 data, such as January 2014 data to July 2017 data and the amount of testing data used is August 2017 to November 2018 data. Training data is used to form the throughput forecasting model and Testing data is used to test the accuracy of the model that has been built. This forecasting is done by combining the type of FIS, membership functions and the number of membership functions to obtain the best model based on the criteria of RMSE, MSE, and MAPE.

\section{Forecasting Throughput Data}

The following graphs are the results of container data training, export traffics and the Stuff traffics from the best models respectively shown in Figures 7, 8, and 9.

Based on Figure 7 which shows the graph of training data throughput results it can be seen that container forecasting using TS-ANFIS obtained the best results in the second experiment with MAPE of $11.65 \%$. This shows that the model formed using genfis2 with a radius of 0.1 has a good performance in predicting data with MAPE calculations that are limit to $10 \%$.

In the graph of the export traffic data training results shown in Figure 8, it can be seen that forecasting export traffics gets the best results in the third experiment using genetic parameters 3 with a number of membership function $(\mathrm{mf})=4$ and a maximum iteration of 1000 . The forecast has a MAPE error value of $26.70 \%$ means that the forecasting model formed has a reasonable forecasting performance with a MAPE error value between $20-50 \%$.

Forecasting the traffic of goods using TS-ANFIS gets the best model with the parameters genfis 2 , radius $=0.2$ and the maximum iteration is 1000 epoch. The model obtained from the forecasting has a MAPE error value of $21.87 \%$. Similar to forecasting export traffics, forecasting of goods traffics also has a quite relevant forecasting because MAPE error values are in the range of $20-50 \%$. The red line on the top graph shows the predicted results while the black line shows the 
The $1^{\text {st }}$ International Conference on Business and Engineering Management (IConBEM)

February $1^{\text {st }} 2020$, Institut Teknologi Sepuluh Nopember, Surabaya, Indonesia

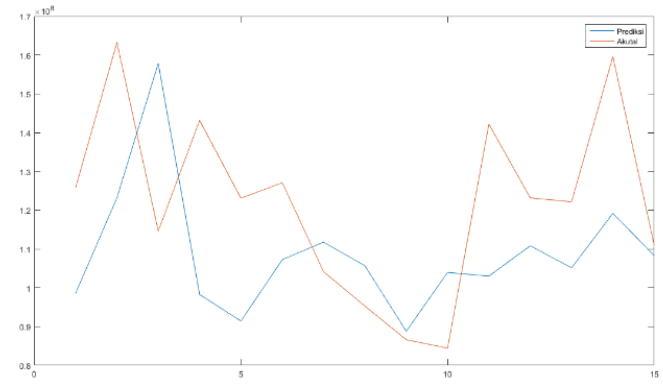

Figure 10: Profit Prediction Using Genfis1.

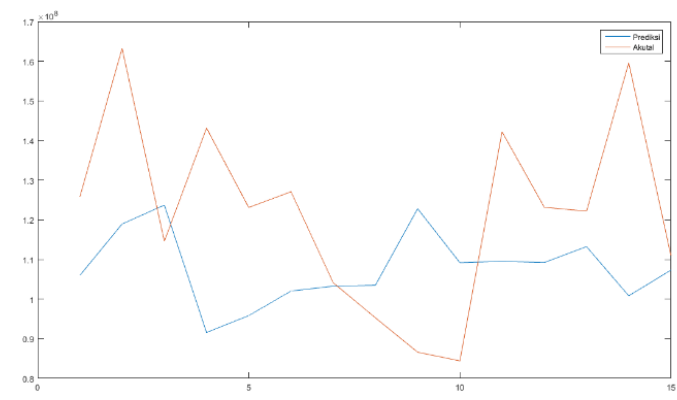

Figure 11: Profit Prediction Using Genfis2.

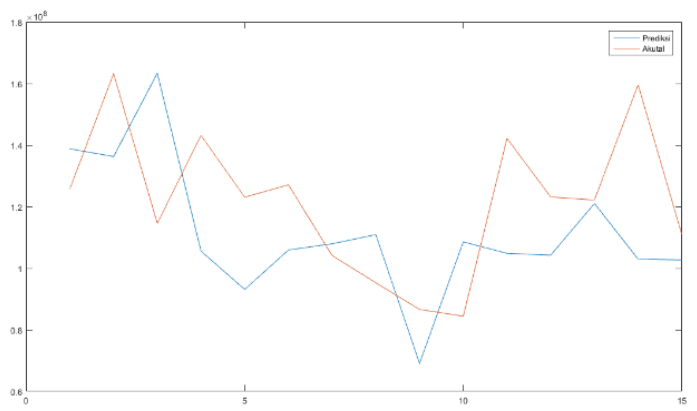

Figure 12: Profit Prediction Using Genfis3.

target of the forecast. The testing process uses the best model obtained. The testing process was carried out using 14 data (data from August 2017 to November 2018) which was applied to the model that was obtained from the training process in several experiments with a maximum iteration of 1000 and an error goal of 0.000001 . Evaluation of forecast results is done through three criteria, such as MSE, RMSE and MAPE. The evaluation process uses functions contained in MATLAB. The results of the testing process are shown in Table 5.

Based on the experimental results shown in Table 5, each parameter gets the best results using two types of FIS, such as genfis1 and genfis2. The MAPE error value obtained by the Container parameter is $11.65 \%$, which means that the formed model has good performance because the value is close to $10 \%$. Parameters Export traffics and goods traffic have error values that are in the range of $20-50 \%$, which means that the forecast made is quite reasonable. The results of this forecast throughput will be used to predict profit.

\section{Profit Prediction Based on Forecasting Each Throughput using ANFIS}

In this research, the prediction of Tanjung Perak Port's corporate profit using the Adaptive Neuro Fuzzy Inference System (ANFIS) method. Forecasting using ANFIS is done through two stages, such as training and testing. The training
Table 8:

Profit Forecasting Results with Genfis 2

\begin{tabular}{clccc}
\hline \hline Radius & $\boldsymbol{R}^{\mathbf{2}}$ & RMSE & MAPE & MAAPE \\
\hline 0.1 & 0,892 & 40783077,44 & $22,42 \%$ & 0,218 \\
0.2 & 0,845 & 48700383,29 & $24,27 \%$ & 0,231 \\
0.3 & 0,931 & 32654491,35 & $15,62 \%$ & 0,152 \\
0.4 & 0,928 & 33188790,15 & $17,04 \%$ & 0,166 \\
0.5 & 0,942 & 29737558,27 & $14,91 \%$ & 0,146 \\
\hline
\end{tabular}

Table 9:

Profit Forecasting Results with Genfis 3

\begin{tabular}{clccc}
\hline \hline Cluster & $\boldsymbol{R}^{\mathbf{2}}$ & RMSE & MAPE & MAAPE \\
\hline 2 & 0,947 & 28524582,39 & 14,74 & 0,145 \\
3 & 0,756 & 61136363,74 & 23,53 & 0,209 \\
4 & 0,931 & 32492291,07 & 17,17 & 0,168 \\
5 & 0,301 & 103529500,4 & 42,55 & 0,343 \\
6 & 0,918 & 35463758,63 & 19,43 & 0,190 \\
7 & 0,745 & 62495101,74 & 26,92 & 0,243 \\
8 & 0,623 & 76055984,07 & 34,78 & 0,308 \\
9 & 0,715 & 66157427,24 & 28,05 & 0,250 \\
10 & 0,454 & 91522992,85 & 46,05 & 0,401 \\
\hline \hline
\end{tabular}

process is carried out with various combinations of variables that become experiments to get the best model. The model will be applied to the testing data to calculate the evaluation of the model. The data used as input is the company's timeseries data throughput that has been previously processed. These results become profit prediction data from the Port of Tanjung Perak Surabaya.

The results of a profit forecasting experiment are presented in the table. Each table has different ANFIS parameter criteria. Table 6 and 7 shows the results of experiments from ANFIS using grid partitioning with variations in the number of membership functions commonly known as genfis 1 .

In profit forecasting using ANFIS with genfis1 looks pretty good. The result of the combination of membership function type between gaussian and generalized bell shows that gaussian has better forecasting performance than generalized bell. This is evidenced by the large MAPE error value which is almost close to $10 \%$ which is $14.96 \%$ and the value of the criteria $\mathrm{R}^{\wedge} 2$ in the gaussian experiment with $2 \mathrm{mf}$ of 0.942 is almost close to 1 . The value of $\mathrm{R}^{\wedge} 2$ is getting closer to 1 so it can be said that the model built is very well. Vice versa, if the value of $R^{\wedge} 2$ is getting closer to 0 then the model is built poorly. If there is a negative $\mathrm{R}^{\wedge} 2$ value then it can be said that the model is very bad. Like an experiment on a generalized bell with $3 \mathrm{mf}$, it appears that the value of $\mathrm{R}^{\wedge} 2$ is negative or less than 0 meaning that the model formed from this forecast is very bad. The MAPE error value obtained is also very large, namely $525.91 \%$. This figure is very far from the MAPE criteria standard. The profit forecast graph of the best model using Genfis 1 is shown in Figure 10.

In figure 10, the red line shows the original data (target) in forecasting, while the blue line shows the results of profit prediction using ANFIS. Based on the graph shown in Figure 4.4 , it appears that there are a number of months that have different results than the intended target. But the range of values is not too far from the target. While the results of profit forecasting using Genfis 2 are shown in Table 8.

Based on table 8 , which presents the results of forecasting profits using Genfis 2 with a combination of radius shows the best results at a radius of 0.5 with $\mathrm{R} \wedge 2$ of 0.942 , RMSE 29737558.27, MAPE $14.91 \%$ and MAAPE 0.146. A value of 
The $1^{\text {st }}$ International Conference on Business and Engineering Management (IConBEM)

February $1^{\text {st }} 2020$, Institut Teknologi Sepuluh Nopember, Surabaya, Indonesia

$\mathrm{R}^{\wedge} 2$ which is almost close to 1 means that the model built is very good and a MAPE value that is close to $10 \%$ means that the performance of the model is also good. But the RMSE value is still quite high. This happens because the prediction value is very high in units of tens of millions so the possibility of error is also high which results in high RMSE values. Whereas the results of forecasting profits using Genfis 3 are shown in Table 8 . The graph of forecasting profits from the best models using Genfis 2 is shown in Figure 11.

In figure 11, the red line shows the original data (target) in forecasting, while the red line shows the results of profit prediction using ANFIS. Based on the graph shown in Figure 4.5 , it can be seen that there are many differences between the predicted results and the intended targets. The results of profit forecasting using Genis 3 are shown in Table 9.

The results of port profit forecasting using Genfis 3 with the number of clusters experiments shown in Table 4.7 shows that the best results with the number of clusters 2 get the highest $R^{2}$ value among the other genres, namely 0.947, MAPE at $14.74 \%$, RMSE at 28524582.39, and MAAPE equal to 0.145 therefore the profit forecasting model using ANFIS is the best model from Genfis 3. The profit forecast graph of the best model using Genfis 3 is shown in Figure 12.

In figure 4.6, the red line shows the original data (target) in forecasting, while the red line shows the results of profit prediction using ANFIS. Based on the graph shown in Figure 4.6 , it appears that there are many differences.

\section{CONCLUSION}

Throughput data forecasting using ANFIS method obtained the best model for container data with genetic 2, radius 0.1 obtained an MSE value of 4543.6, an RMSE of 67.40 and a MAPE of $11.65 \%$. Forecasting export traffics using Genfis 3 with the parameter used is FCM, the number of clusters of 3 and 4 mf obtains an MSE $4.30 \times 10^{-10}$, RMSE $4.30 \times 10^{-10}$, and MAPE $26.70 \%$. forecasting using Genfis 2 with a radius of 0.2 obtains an MSE $9.89 \times 10^{-13}$, RMSE $9.94 \times 10^{-7}$, and MAPE $21.87 \%$. Predictions of the benefits of the Tanjung Perak Port Surabaya using ANFIS with various parameter experiments get the best model using the FCM approach with the number of clusters as much as 2 obtaining $\mathrm{R}^{2} 0.947$, RMSE 28524582.39, MAPE 14.74\%, and MAAPE 0.145. Prediction models formed using ANFIS have good performance because the MAPE error values obtained are in the range of $20 \%-10 \%$. This is supported by the value of $\mathrm{R}^{2}$ which is limit to 1 meaning that the model formed is very good. So this model can be said to be suitable for the profit prediction of Surabaya's Tanjung Perak Port. From the prediction results, it can be used as a reference for company projections in investing, managing cash flow, managing assets and global bonds which have various benefits and risks.

\section{REFERENCES}

[1] D. A. Yeremia, "Peranan Sektor Maritim Dalam Perekonomian Indonesia," Universitas Airlangga, 2017.
[2] C. Zhang, L. Huang, and Z. Zhao, "Research on combination forecast of port cargo throughput based on time series and causality analysis," vol. 6, no. 1, pp. 124-134, 2013.

[3] X. Zha, Y. Chai, F. Witlox, and L. Ma, "Container Throughput Time Series Forecasting Using a Hybrid Approach,” vol. 281, pp. 639-650, 2016.

[4] H. K. Chan, S. Xu, and X. Qi, "A comparison of time series methods for forecasting container throughput," Int. J. Logist. Res. Appl., vol. 0, no. 0 , pp. 1-10, 2018.

[5] Z. Jin and Y. Ding, "Prediction of Container Throughput in China," pp. 12-20, 2018.

[6] X. Dong, W. Fan, and J. Gu, "Predicting LTE Throughput Using Traffic Time Series," ZTE Commun., vol. 13, pp. 61-64, 2015.

[7] P. Ghosh, "Machine Learning TrendsNo Title," Dataversity, 2017.

[8] J. Singh and P. Tripathi, "Time Series Forecasting Using Back Propagation Neural Network with ADE Algorithm," vol. 0869, no. 5, pp. 19-23, 2017.

[9] M. A. Boyacioglu and D. Avci, "An adaptive network-based fuzzy inference system (ANFIS) for the prediction of stock market return: The case of the Istanbul stock exchange," Expert Syst. Appl., vol. 37, no. 12, pp. 7908-7912, 2010.

[10] D. A. Adyanti, A. H. Asyhar, D. C. R. Novitasari, A. Lubab, and M. Hafiyusholeh, "Forecasts marine weather on java sea using hybrid methods: Ts-anfis," Int. Conf. Electr. Eng. Comput. Sci. Informatics, vol. 4, no. September, pp. 492-497, 2017.

[11] I. Svalina, V. Galzina, R. Lujić, and G. Šimunović, "An adaptive network-based fuzzy inference system (ANFIS) for the forecasting: The case of close price indices," Expert Syst. Appl., vol. 40, no. 15, pp. 6055-6063, 2013.

[12] S. Chabaa, "ANFIS Method for Forecasting Internet Traffic Time Series," 2009.

[13] R. Hidayat, "Meminimalisasi nilai error peramalandengan algoritma," pp. 187-192, 2012.

[14] M. S. Ubay, "Peramalan Harga Saham Dengan Menggunakan Jaringan Syaraf Tiruan Metode Extreme Learning Machine," Unoversitas Airlangga, 2012.

[15] S. Sehgal, H. Singh, M. Agarwal, and V. B. Shantanu, "Data Analysis Using Principal Component Analysis," no. 2, pp. 45-48, 2014.

[16] D. Kashyap, A. Somani, and J. Shekhar, "Cervical Cancer Detection And Classification Using Independent Level Sets And Multi SVMs," pp. 523-528, 2016.

[17] N. A. Qureshi, V. Suthar, H. Magsi, and M. J. Sheikh, "Application of Principal Component Analysis ( PCA ) to Medical Data," vol. 10, no. May, 2017.

[18] F. M. Kusuma and A. Wibowo, "Principal Component Analysis (PCA) Untuk Mengatasi Multikolinieritas Terhadap Faktor Angka Kejadian Pneumonia Balita Di Jawa Timur tahun 2014," J. Biometrika dan Kependud., vol. 6, no. 2, pp. 89-97, 2017.

[19] K. and K. P. P.M., "Daily rainfall forecasting using Adaptive NeuroFuzzy inference system (ANFIS) models.," International J. Sci. Nature., vol. 6., no. 3, pp. 382-388, 2015.

[20] G. Evren, "Adaptive Neuro Fuzzy Inference System (ANFIS) Applications in Chemical Processes," The Middle Eact Technical University, 2003.

[21] D. C. R. Novitasari, M. H. Bisri, and A. H. Asyhar, "Classification of EEG Signals using Fast Fourier Transform ( FFT ) and Adaptive Neuro-Fuzzy Inference System ( ANFIS )," vol. 5, no. 1, pp. 36-45, 2019.

[22] W. Chen, M. Panahi, K. Khosravi, H. Reza, and F. Rezaie, "Spatial prediction of groundwater potentiality using ANFIS ensembled with teaching-learning-based and biogeography-based optimization," $J$. Hydrol., vol. 572, no. February, pp. 435-448, 2019.

[23] E. Özer, A. Akgündo, and A. Ersoy, "Prediction of dust particle size e ff ect on e ffi ciency of photovoltaic modules with ANFIS: An experimental study in Aegean region, Turkey," vol. 177, no. December 2018, pp. 690-702, 2019.

[24] N. K. Singh, Y. Singh, S. Kumar, and A. Sharma, "Materials Today: Proceedings Predictive analysis of surface roughness in EDM using semi-empirical , ANN and ANFIS techniques : A comparative study," Mater. Today Proc., no. xxxx, 2019. 